\title{
Synergistic effects of 5-aminolevulinic acid based photodynamic therapy and celecoxib via oxidative stress in human cholangiocarcinoma cells
}

This article was published in the following Dove Press journal:

International Journal of Nanomedicine

II June 2013

Number of times this article has been viewed

\author{
Cy Hyun Kim ${ }^{1,2, *}$ \\ Chung-Wook Chungl,* \\ Hye Myeong Lee' \\ Do Hyung Kim ${ }^{1,2}$ \\ Tae Won Kwak' \\ Young-IL Jeong' \\ Dae Hwan Kang ${ }^{1,2}$
}

'National Research and Development Center for Hepatobiliary Cancer,

Research Institute for Convergence of Biomedical Science and Technology,

Yangsan, Republic of Korea; ${ }^{2}$ School of Medicine, Pusan National University

Yangsan Hospital, Yangsan, Republic

of Korea

*These authors contributed equally to this work
Correspondence: Dae Hwan Kang National Research and Development Center for Hepatobiliary Cancer, Research Institute for Convergence of Biomedical Science and Technology, Pusan National University Yangsan Hospital, Yangsan, Geumo-ro-20, Mulgeum-eup, Yangsan, Gyeongnam, 626-770,

Republic of Korea

$\mathrm{Tel}+82553603870$

Fax +82 553603879

Email sulsulpul@naver.com

\begin{abstract}
Aminolevulinic acid (ALA)-based photodynamic therapy (PDT) has the potential to kill cancer cells via apoptotic or necrotic signals that are dependent on the generation of intracellular reactive oxygen species (ROS). Celecoxib is an anti-inflammatory drug that induces intracellular ROS generation. We investigated whether the combined application of celecoxib and ALA-PDT improved the efficacy of PDT in human cholangiocarcinoma cells and in tumor bearing mice. In vitro, combined treatment of celecoxib and ALA-PDT increased phototoxicity and intracellular ROS levels after irradiation with $0.75 \mathrm{~J} / \mathrm{cm}^{2}$ when compared to ALA-PDT alone. Even though ROS levels increased with $0.25 \mathrm{~J} / \mathrm{cm}^{2}$ of irradiation, it did not influence phototoxicity. When heme oxygenase-1, a defensive protein induced by oxidative stress, was inhibited in the combined treatment group, phototoxicity was increased at both $0.25 \mathrm{~J} / \mathrm{cm}^{2}$ and $0.75 \mathrm{~J} / \mathrm{cm}^{2}$ of irradiation. We identified the combined effect of ALA-PDT and celecoxib through the increase of oxidative stress such as ROS. In vivo, about $40 \%$ tumor growth inhibition was observed with combined application of ALA-PDT and celecoxib when compared to ALA-PDT alone. The combined application of ALA-PDT and celecoxib could be an effective therapy for human cholangiocarcinoma. Moreover, use of a heme oxygenase-1 inhibitor with PDT could play an important role for management of various tumors involving oxidative stress.
\end{abstract}

Keywords: celecoxib, aminolevulinic acid, reactive oxygen species, photodynamic therapy, human cholangiocarcinoma

\section{Introduction}

Photodynamic therapy (PDT) with photosensitizers is an effective therapeutic method for various benign or malignant tumors. ${ }^{1-8} 5$-Aminolevulinic acid (ALA) is frequently used with PDT because ALA can be interconverted to a potent photosensitizer, protoporphyrin IX (PpIX), via the heme biosynthetic pathway in mitochondria. ${ }^{3-6,9,10}$ Excitation of a photosensitizer by irradiation with a suitable light source can produce a significant amount of reactive oxygen species (ROS). ${ }^{9,10}$ ROS elicit DNA and cell membrane damage through lipid peroxidation/alterations in membrane fluidity. The damage to cellular organelles, such as mitochondria and microsomes, can be harnessed to increase the death of tumor cells. ${ }^{11-14}$

The clinical use of ALA has been hampered by its highly hydrophilic character, which makes penetration into the hydrophobic interior of cell membranes very difficult. ${ }^{13}$ Approaches that have been explored to overcome this barrier in the use of ALA-PDT include the addition of hydrophobic moieties or enhancers to ALA, or coupling of ALA to a carrier. ${ }^{15-18}$ 
In a previous study, we demonstrated the success of ALAPDT in inhibiting human cholangiocarcinoma (HuCC-T1) cells through increased intracellular ROS levels. ${ }^{19}$ This result prompted interest in the importance of intracellular ROS in enhancing the efficacy of ALA-PDT, which led to the consideration of celecoxib in combination with ALAPDT. Celecoxib is a new generation nonsteroidal antiinflammatory drug that selectively inhibits cyclooxygenase-2 activity. It is an effective drug for the treatment of pain and inflammation..$^{20,21}$ Recent studies have shown that celecoxib inhibits the progression of colon tumors in human and animal models, inhibits the growth of several other tumor cell types, such as breast cancer, osteosarcoma, and gastric cancer in vitro, and induces mitochondrial ROS in human umbilical vein endothelial cells. ${ }^{1,2,7,8,11}$

In this study, we investigated whether or not the combined application of celecoxib and ALA-PDT could elevate the phototoxic effects against HuCC-T1 cells in comparison to ALA-PDT alone. Attention was paid to heme oxygenase-1 (HO-1) protein, which is an inducible protein against oxidative stress. HO-1 confers cytoprotection against oxidative injury and cellular stress both in vitro and in vivo. ${ }^{1,10,22}$ To our knowledge, the effect of the combined application of ALA-PDT and celecoxib has not been reported. We also investigated whether or not the combined therapy effect was promoted by oxidative stress via the inhibition of HO-1 expression.

\section{Methods and materials}

\section{Chemicals}

ALA, 2',7'-dichlorofluorescein diacetate (DCFH-DA), 3-[4,5-dimethylthiazol-2-yl]-2,5-diphenyltetrazolium bromide (MTT), propidium iodide (PI), PpIX, secondary antibody, and protein kinase $\mathrm{C}$ (PKC) inhibitor were purchased from Sigma-Aldrich (St Louis, MO, USA). Celecoxib was purchased from LC Laboratories (Woburn, MA, USA) and was prepared by dissolving in DMSO. HO- $1, \beta$-actin antibody, and HO-1 shRNA or control shRNA small hairpin RNA (shRNA) was obtained from Santa Cruz Biotechnology (Dallas, TX, USA). Fluorescein isothiocyanate (FITC)-annexin $\mathrm{V}$ was obtained from BD (Franklin Lakes, NJ, USA). Cell culture materials, MitoSOX, Mitotracker, Lipofectamine ${ }^{\circledR}$ 2000, and Opti-MEM I ${ }^{\circledR}$ were purchased from Invitrogen (Carlsbad, CA, USA).

\section{Cell culture}

HuCC-T1 cells were obtained from the Health Science Research Resources Bank (Osaka, Japan). Human embryonic kidney cells (HEK 293T) were purchased from the American
Type Culture Collection (Manassas, VA, USA). All cells were propagated for less than 6 months after resuscitation. The experiments were performed when cells reached $80 \%$ confluence in the culture plate. HuCC-T1 and HEK 293T cells were routinely propagated in RPMI (Gibco, Carlsbad, CA, USA) and Dulbecco's Modified Eagles Medium (Gibco), respectively, supplemented with $10 \%$ fetal bovine serum (FBS), 100 units $/ \mathrm{mL}$ penicillin, and $100 \mu \mathrm{g} / \mathrm{mL}$ streptomycin at $37^{\circ} \mathrm{C}$ in a humidified atmosphere of $5 \% \mathrm{CO}_{2}: 95 \%$ air according to a previous procedure. ${ }^{23}$ Cells were subcultured every 3 days and trypsin-EDTA (0.05\% trypsin and $0.02 \%$ EDTA) was used.

\section{Cytotoxicity}

For the cytotoxicity test of ALA or celecoxib, HEK 293T cells were seeded into a 96 well plate $\left(1 \times 10^{4}\right.$ cells/well $)$. HEK $293 \mathrm{~T}$ cells were starved before ALA or celecoxib treatment for 24 hours in starvation medium containing $0.1 \%$ FBS. After washing with phosphate buffered saline (PBS), the cells were treated with $0.5-5 \mathrm{mM}$ ALA and 10-50 $\mu \mathrm{M}$ celecoxib in serum-free medium for 4 hours. The cell viability was measured by MTT assay. Briefly, the cells were treated with fresh medium containing MTT solution (final concentration $0.5 \mathrm{mg} / \mathrm{mL}$ ) and incubated further for 4 hours. Then, $10 \%$ sodium dodecyl sulfate containing $0.01 \mathrm{M}$ hydrochloric acid was added into each well in equal volumes as the medium and incubated for 18 hours. Absorbance was measured at a wavelength of $570 \mathrm{~nm}$ using an Infinite M200 PRO microplate reader (Tecan, Grodig, Austria).

\section{Photodynamic therapy}

To observe phototoxicity, HuCC-T1 cells $\left(1 \times 10^{4}\right.$ cells/ well), in a 96 well plate, were incubated with $100 \mu \mathrm{L}$ of serum-free media containing various concentration of ALA in the absence or presence of celecoxib for 4 hours. After that, light emitting diode (LED) lamps at $635 \mathrm{~nm}$ were used for irradiation (SH Systems, Gwangju, Republic of Korea). The PDT instrument consisted of 270 LED lamps and the light intensity was measured by a photoradiometer (Delta Ohm, Padova, Italy). The cells were irradiated with a fluence of 0.25 or $0.75 \mathrm{~J} / \mathrm{cm}^{2}$, and then the medium was replaced by growth medium containing 10\% FBS. After further incubation for 24 hours, cell viability was measured by a standard MTT assay as described above.

\section{PpIX location and accumulation}

HuCC-T1 cells $\left(1 \times 10^{4}\right.$ cells/well $)$, in a 96-well plate, were incubated with serum-free medium containing various 
concentration of ALA and/or celecoxib for 4 hours. The medium was discarded and the cells were washed twice with PBS. Cells were lysed with a Lipa buffer (GenDEPOT, Barker, TX, USA). PpIX accumulation in cells was measured by fluorescence intensity using the aforementioned Infinite M200 PRO microplate reader at an excitation wavelength of $485 \mathrm{~nm}$ and an emission wavelength of $635 \mathrm{~nm}$. PpIX standard was measured using PpIX compound for analysis of PpIX accumulation in cells. PpIX production was corrected for protein content. The protein assay was performed using a commercial bicinchoninic acid (BCA) protein assay kit according to the manufacturer's instructions (Pierce Pharmaceuticals, Rockford, IL, USA). Cells treated with ALA $(3 \mathrm{mM})$ and/or celecoxib $(10 \mu \mathrm{M})$ were stained using Mitotracker (100 nM) to identify accumulation and location of PpIX. A model FV1000 confocal microscope (Olympus Corporation, Tokyo, Japan) was set to $490 / 516$ or $485 / 635 \mathrm{~nm}$ of excitation/emission wavelengths for detection of Mitotracker or PpIX, respectively.

\section{Flow cytometry}

The cells were treated with ALA and/or celecoxib in serumfree medium for 4 hours. After that, the cells were irradiated with a fluence of 0.25 or $0.75 \mathrm{~J} / \mathrm{cm}^{2}$ at $635 \mathrm{~nm}$. They were collected and washed with PBS. The collected pellets were resuspended with binding buffer (10 mM HEPES, pH7.4, $150 \mathrm{mM} \mathrm{NaCl}, 5 \mathrm{mM} \mathrm{KCl}, 1 \mathrm{mM} \mathrm{MgCl}_{2}$, and $1.8 \mathrm{mM} \mathrm{CaCl}_{2}$ ) containing FITC-annexin V $(1 \mu \mathrm{g} / \mathrm{mL})$ to stain apoptotic cells and were further incubated for 30 minutes. Ten minutes prior to the termination of incubation, PI $(10 \mu \mathrm{g} / \mathrm{mL})$ was added to stain necrotic cells in the dark. The cells were immediately analyzed with a FACScan flow cytometer (Becton Dickenson Biosciences, San Jose, CA, USA).

\section{ROS measurement}

After irradiation, ROS generation from PpIX-accumulated HuCC-T1 cells was measured by the $2^{\prime}, 7^{\prime}$-dichlorofluorescein (DCF) method. ${ }^{24}$ In the assay, the fluorogenic substrate $2^{\prime}, 7^{\prime}$-dichlorofluorescein diacetate (DCFH-DA), a cell permeable dye, is oxidized to highly fluorescent DCF by ROS, which is used to monitor the intracellular generation of ROS. The cells were treated with ALA and/or celecoxib for 4 hours in phenol red free RPMI medium (Gibco). DCFHDA was added to the medium to a final concentration of $20 \mu \mathrm{M}$ and incubated at $37^{\circ} \mathrm{C}$ for 30 minutes. After irradiation with a fluence of 0.25 or $0.75 \mathrm{~J} / \mathrm{cm}^{2}$ at $635 \mathrm{~nm}$, ROS generation was measured by fluorescence at an excitation wavelength of $485 \mathrm{~nm}$ and emission wavelength of $535 \mathrm{~nm}$ using a microplate reader. The ROS data were expressed as a percentage of control. The control cells were treated with DCFH-DA and irradiated with a fluence of $0.25 \mathrm{~J} / \mathrm{cm}^{2}$ at $635 \mathrm{~nm}$.

ROS generation in mitochondria was observed by confocal microscopy using MitoSOX (FV1000, Olympus, Center Valley, PA, USA). HuCC-T1 cells were seeded on a cover glass that was positioned in a 6 well plate. Cells were treated with ALA $(3 \mathrm{mM})$ and/or celecoxib $(10 \mu \mathrm{M})$ in serum-free medium for 4 hours. After that, MitoSOX was added to the cells for 10 minutes before irradiation with a fluence of $0.75 \mathrm{~J} / \mathrm{cm}^{2}$ at $635 \mathrm{~nm}$. The cells were washed with PBS, fixed with $4 \%$ paraformaldehyde, and mounted on a glass slide. The cells were observed by confocal microcopy. The confocal microscope was equipped with a 460-480 nm excitation filter and a $610 \mathrm{~nm}$ filter for detection of MitoSOX.

\section{Western blot}

The cells were lysed on ice with a Lipa buffer (GenDEPOT) for 30 minutes. Cell lysates were centrifuged at $13,000 \times \mathrm{g}$ for 20 minutes at $4^{\circ} \mathrm{C}$. The supernatant was collected and the protein concentration was determined by a BCA protein assay kit. Equal amounts of protein $(50 \mu \mathrm{g})$ were resolved using 4\%-15\% gradient sodium dodecyl sulfate polyacrylamide gel electrophoresis and then transferred to a polyvinylidene fluoride membrane (Millipore, Billerica, MA, USA). The membrane was incubated with $\mathrm{HO}-1$ or $\beta$-actin primary antibody overnight at $4^{\circ} \mathrm{C}$, washed with PBS, and incubated with a horseradish peroxidase-conjugated mouse secondary antibody for 1 hour at room temperature. The immunoblots were visualized by chemiluminescence horseradish peroxidase substrate (Pierce Pharmaceuticals).

\section{shRNA plasmid transfection}

HO-1 shRNA plasmid is a pool of three target specific lentiviral vector plasmids each encoding 19-25 nucleotides (plus hairpin) shRNAs designed to knock down gene expression. Cells $\left(5 \times 10^{3}\right.$ cells/well $)$ were seeded in a 96 well plate. Cells were transfected with HO-1 or control shRNA using Lipofectamine ${ }^{\circledR}$ 2000. shRNA was diluted in $50 \mu \mathrm{L}$ Opti-MEM I ${ }^{\circledR}$. The final concentration of RNA was $33 \mathrm{nM}$ in each well. Lipofectamine ${ }^{\circledR} 2000$ was diluted $1 \mu \mathrm{L}$ in $50 \mu \mathrm{L}$ Opti-MEM I ${ }^{\circledR}$ and incubated for 5 minutes. Then, the two prepared reagents were mixed and incubated for 20 minutes. These complexes were added to each well containing cells and medium. Experiments were carried out 24 hours after transfection. 


\section{Xenograft mouse induced by HuCC-TI cells}

Four week old male BALB/c nude mice were purchased from Orientbio, Inc (Seongnam, Republic of Korea). HuCC-T1 cells $\left(1 \times 10^{7}\right.$ cells/well $)$ in $100 \mu \mathrm{L}$ of serum-free medium were subcutaneously injected into the backs of mice as described. ${ }^{25}$ After 3 weeks, when the tumors had attained an average diameter of approximately $6 \mathrm{~mm}$, ALA $(100 \mathrm{mg} / \mathrm{kg})$ and $/$ or celecoxib $(5 \mathrm{mg} / \mathrm{kg}$ ) were used to treat the tumors $(\mathrm{n}=8 \mathrm{each})$. The drugs, in a $50 \mu \mathrm{L}$ volume, were directly injected into each tumor area. ${ }^{26-31}$ At 4 hours after treatment, mice were irradiated with a fluence of $2 \mathrm{~J} / \mathrm{cm}^{2}$. Tumor volumes and body weights were measured every 3-4 days from 2 weeks after PDT. Tumor volumes were calculated by the formula (length $)^{2} \times($ width $/ 2)$.

\section{Immunohistochemistry}

Tumors were dissected 42 days after PDT. These tumors were fixed in $4 \%$ formalin, embedded in paraffin, and sectioned at a thickness of $4 \mu \mathrm{m}$. After being deparaffinized, sections were stained with hematoxylin-eosin (H\&E) or were used for terminal deoxynucleotidyl transferase dUTP nick end labeling (TUNEL) with 3,3'-diaminobenzidine (DAB) as the chromogen, to observe morphology or identify apoptotic cells in tumor tissues, respectively. Nuclear counterstaining was carried out with hematoxylin. All animals were treated and handled according to the Recommendations for the Handling of Laboratory Animals for Biomedical Research and complied with the Committee of the Safety and

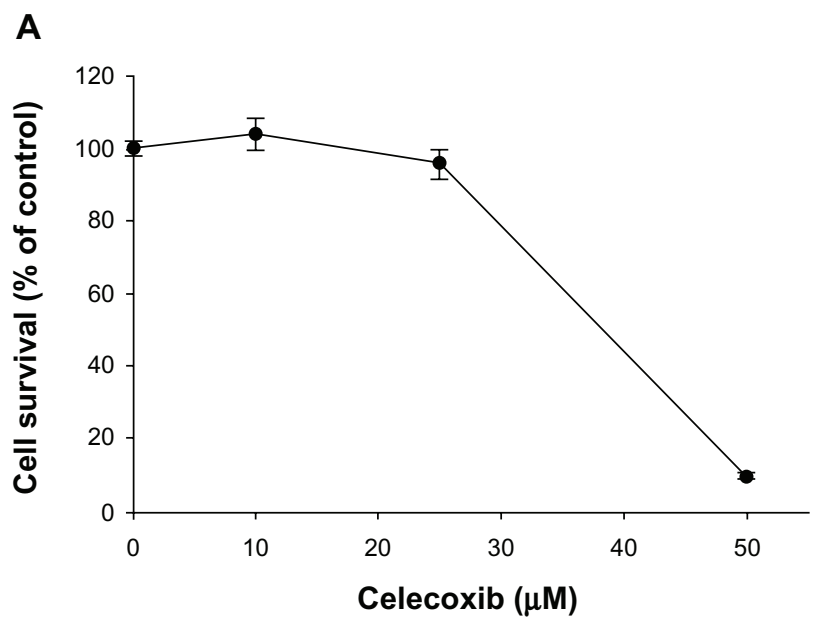

Handling Regulations for Laboratory Animal Experiments in our Institute.

\section{Statistical analysis}

All experiments were performed at least in triplicate. All data are expressed as the mean \pm standard error of mean (SEM) of the independent experiments. Statistical analysis was performed by ANOVA followed by Tukey's post hoc test.

\section{Results}

\section{Dark toxicity in combined treatment of ALA and celecoxib}

Prior to investigation of dark toxicity, the cytotoxicity and anticancer activity of celecoxib was tested in HEK 293T and HuCC-T1 cells, respectively. When HEK 293T cells were treated with $\leq 25 \mu \mathrm{M}$ celecoxib for 4 hours, no cytotoxicity was evident and cell survival exceeded $95 \%$ of the control (Figure 1A). Cytotoxicity of ALA (0.5-5 mM) was not exhibited in HEK 293T cells (Figure S1). Anticancer activity of celecoxib was not evident in HuCC-T1 cells treated with $\leq 25 \mu \mathrm{M}$ celecoxib (Figure 1B). To confirm dark toxicity, various concentrations of $\operatorname{ALA}(0.5,1$, and $3 \mathrm{mM})$ in the absence or presence of celecoxib $(10,25$, and $50 \mu \mathrm{M}$ ) were used to treat HuCC-T1 cells for 4 hours in the dark. As shown in Figure 1B, cell survival was not affected by a single treatment of ALA without irradiation. Furthermore, when celecoxib was applied along with ALA to HuCC-T1 cells without irradiation, cell survival was affected only by celecoxib.
B

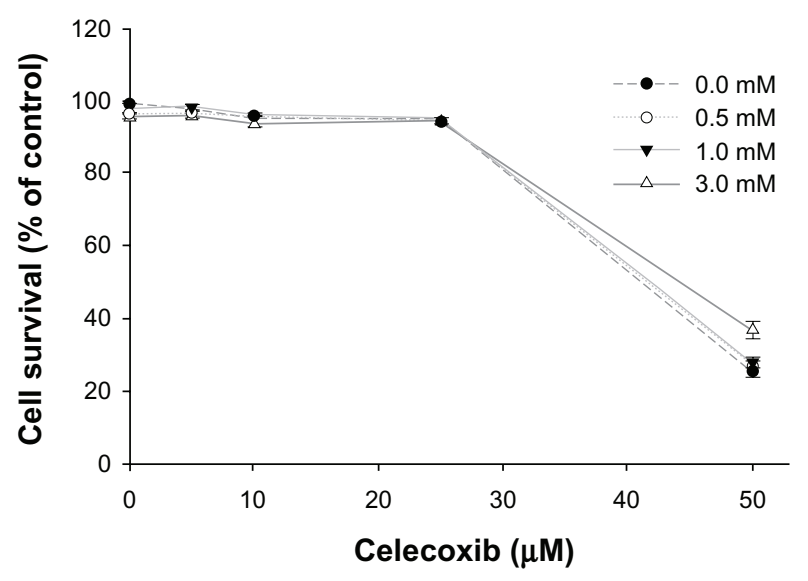

Figure I Cytotoxicity of celecoxib and dark toxicity of 5-aminolevulinic (ALA) acid and/or celecoxib.

Notes: (A) HEK 293 T cells were starved for 24 hours in medium containing $0.1 \%$ fetal bovine serum. The cells were treated with various concentrations of celecoxib for 4 hours in medium containing $0.1 \%$ fetal bovine serum. Cell survival was determined by the MTT assay. (B) HuCC-TI cells were treated with various concentrations of ALA and/or celecoxib for 4 hours in serum-free medium without light. Cell survival was measured by the MTT assay. Error bars represent mean \pm SEM. 


\section{PpIX production by combined treatment of ALA and celecoxib}

PpIX accumulation in HuCC-T1 cells, induced by a 4 hour treatment with ALA and/or celecoxib, was observed by fluorescence intensity. As shown in Figure 2A, the amount of intracellular PpIX increased according to the ALA dose. When $0.5 \mathrm{mM}$ or $1 \mathrm{mM}$ ALA was applied with various concentrations of celecoxib, PpIX production decreased with increasing celecoxib concentration. The accumulation of PpIX in the presence of $3 \mathrm{mM}$ ALA was not affected by the existence of celecoxib (Figure 2B). For this reason, ALA concentration was fixed at $3 \mathrm{mM}$ in later studies. PpIX location was identified in subcellular mitochondria (Figure 2C).

\section{Cell death induced by combined treatment of ALA-PDT and celecoxib}

As shown in Figure 3A, the low intensity of light $\left(0.25 \mathrm{~J} / \mathrm{cm}^{2}\right)$ did not affect cell survival following increasing celecoxib concentration combined with ALA. Cell survival exceeded $95 \%$, even in the presence of $3 \mathrm{mM}$ ALA and $25 \mu \mathrm{M}$ celecoxib.
At a dose of $0.75 \mathrm{~J} / \mathrm{cm}^{2}$, cell death was successfully induced. When the cells were cotreated with $3 \mathrm{mM} \mathrm{ALA}$ and 10 or $25 \mu \mathrm{M}$ celecoxib, cell survival decreased $(66 \% \pm 5.6 \%$ and $62 \% \pm 5.7 \%$, respectively) when compared with the ALA only treated group $(87 \% \pm 1.2 \%)$. These results indicate that combined treatment of celecoxib and ALA-PDT can induce stronger cell phototoxicity than ALA-PDT alone under a suitable light intensity.

\section{ROS generation by combined treatment of ALA-PDT and celecoxib}

As shown in Figure 3B, 3 mM ALA could successfully induce ROS production. ROS generation at a light intensity of 0.25 and $0.75 \mathrm{~J} / \mathrm{cm}^{2}$ was $318 \% \pm 8.7 \%$ and $431 \% \pm 15.0 \%$, respectively. A single treatment of celecoxib (10 or $25 \mu \mathrm{M})$ induced very low ROS generation. ROS generation was increased markedly in the cotreated group when compared to ALA alone, regardless of the light power. Especially, it was elevated when $3 \mathrm{mM}$ ALA was applied to HuCC-T1 cells in combination with $10 \mu \mathrm{M}$ celecoxib $(490 \% \pm 18.9 \%)$ or $25 \mu \mathrm{M}$ celecoxib $(572 \% \pm 11.7 \%)$ at $0.75 \mathrm{~J} / \mathrm{cm}^{2}$, ie, ROS generation
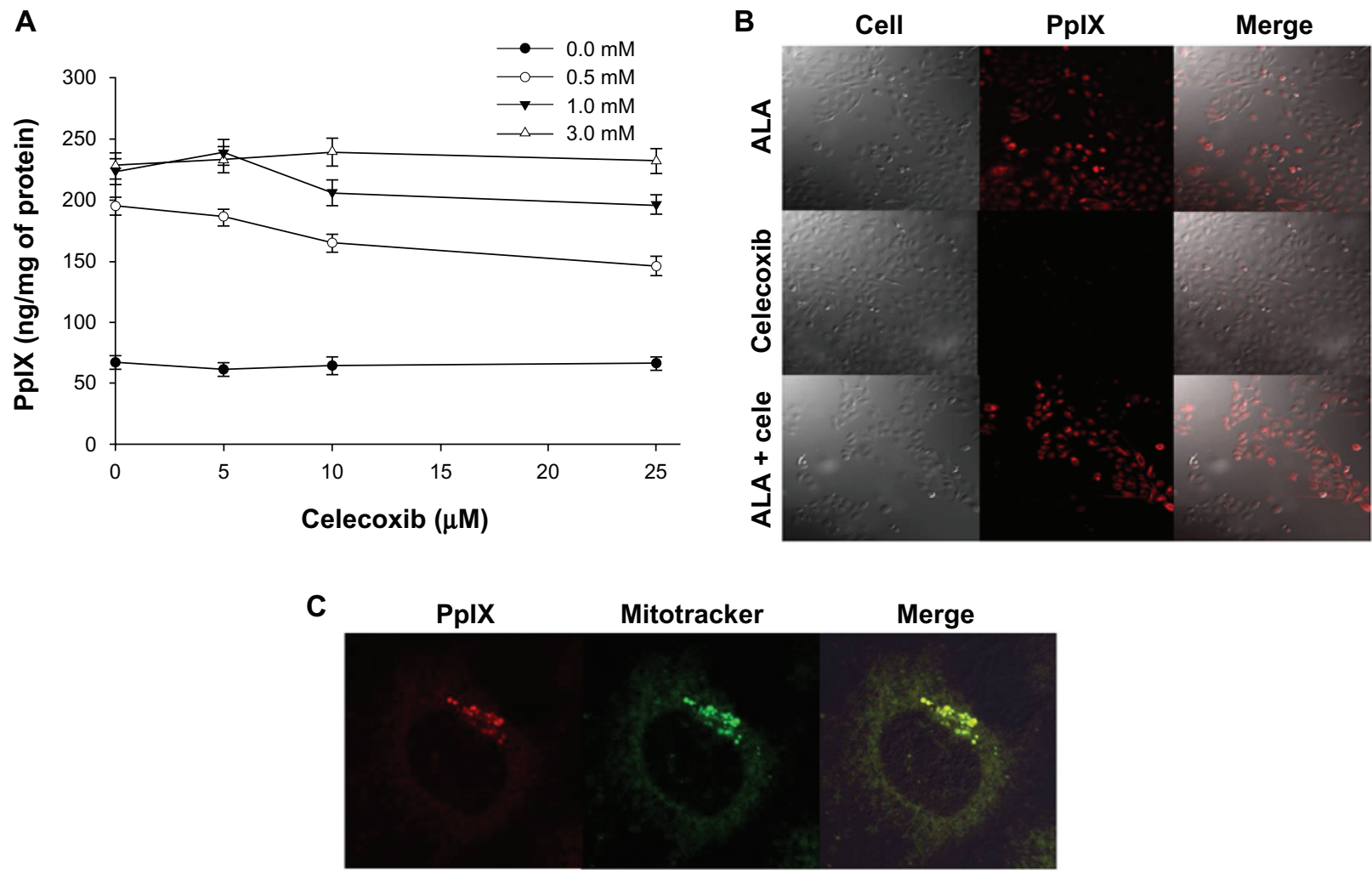

Figure 2 Protoporphyrin IX (PpIX) accumulation with treatment of 5-aminolevulinic acid (ALA) and/or celecoxib.

Notes: (A) HuCC-TI cells were treated with various concentrations of ALA and/or celecoxib for 4 hours in serum-free medium without light. Cells were then lysed and PpIX was analyzed using a microplate reader $(485 / 635 \mathrm{~nm})$. PplX production was corrected for protein content. Data are represented as mean \pm SEM. (B) Photomicrographs exhibited PpIX accumulation by ALA ( $3 \mathrm{mM})$ and/or celecoxib (I0 $\mu \mathrm{M})$. (C) PpIX interconverted by ALA (3 mM) was located in mitochondria when stained with Mitotracker (I00 $\mathrm{nM})$. Abbreviations: ALA, 5-aminolevulinic acid; PpIX, protoporphyrin IX. 
A

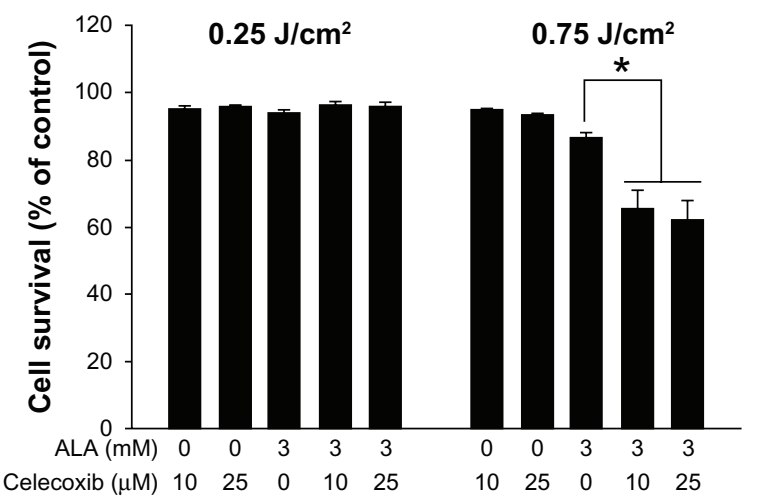

B

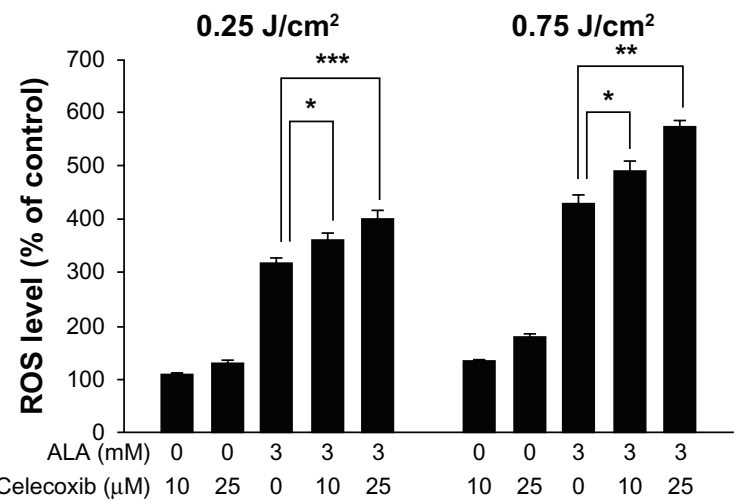

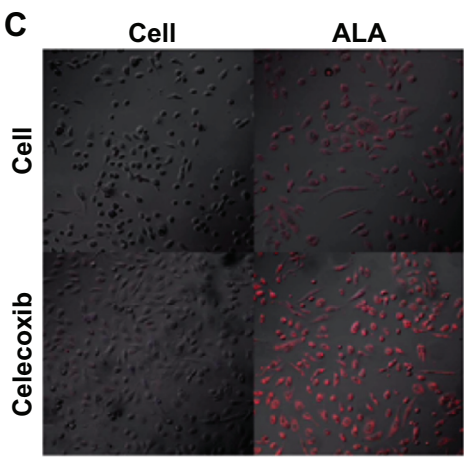
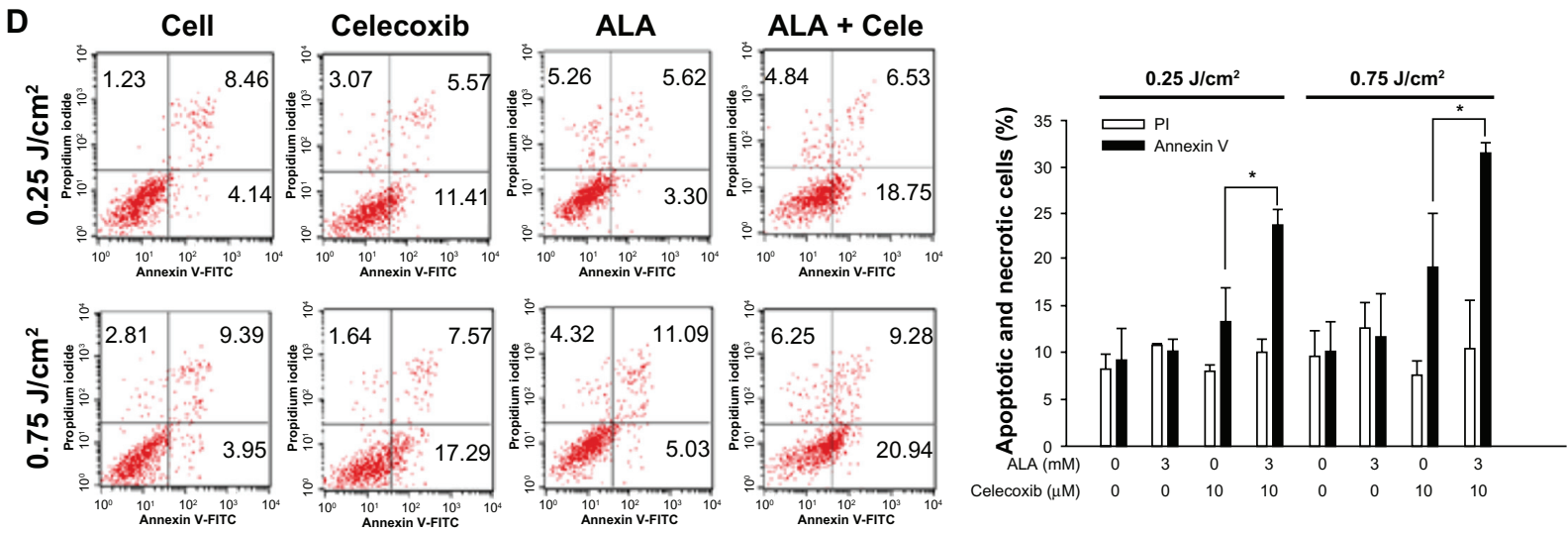

Figure 3 Cell death and reactive oxygen species (ROS) levels after photodynamic treatment (PDT) with 5-aminolevulinic acid (ALA) and/or celecoxib.

Notes: HuCC-TI cells were treated with ALA ( $3 \mathrm{mM}$ ) and/or celecoxib (10 or $25 \mu \mathrm{M})$ for 4 hours in serum-free medium. (A) After irradiation, the cells were incubated for 24 hours in growth medium containing 10\% fetal bovine serum. Cell survival was determined by the MTT assay (error bars represent \pm SEM). (B) The ROS level was measured immediately after irradiation. (C) Cells were treated with ALA ( $3 \mathrm{mM})$ and/or celecoxib (10 $\mu \mathrm{M})$. MitoSOX was used to observe ROS generation in mitochondria by confocal microscopy. After irradiation, cells were incubated for 10 minutes at $37^{\circ} \mathrm{C}$ with MitoSOX $(5 \mu \mathrm{M})$ and washed with phosphate buffered saline. Cells were fixed with $4 \%$ paraformaldehyde and mounted on a slide glass. (D) HuCC-TI cells were treated with ALA ( 3 mM) and/or $10 \mu M$ celecoxib for 4 hours. Propidium iodide and annexin $\mathrm{V}$ were used to detect early apoptosis and necrosis of HuCC-TI cells. After irradiation, cells were collected immediately and washed with phosphate buffered saline. The collected pellets were stained with propidium iodide and fluorescein isothiocyanate-annexin $\mathrm{V}$ and analyzed with a FACScan flow cytometer. Error bars represent \pm SEM; * denotes $P<0.05$; ** denotes $P<0.01$; and *** denotes $P<0.001$.

Abbreviations: ALA, 5-aminolevulinic acid; cele, celecoxib.

was significantly affected by the light dose and combined drug treatment. We also observed ROS generation in mitochondria using MitoSOX, which stains ROS only in the mitochondria. As shown in Figure 3C, MitoSOX staining was intense with the combined treatment of $3 \mathrm{mM}$ ALA and $10 \mu \mathrm{M}$ celecoxib at $0.75 \mathrm{~J} / \mathrm{cm}^{2}$ when compared to ALA or celecoxib alone.

\section{Apoptosis and necrosis induced by combined treatment of ALA-PDT and celecoxib}

As shown in Figure 3D, early apoptotic cells were increased in the combined application ( $23.6 \%$ or $31.4 \%$ ) when compared with the ALA single treatment (10.2\% or $11.7 \%)$. The com- 
bination of $3 \mathrm{mM}$ ALA and $10 \mu \mathrm{M}$ celecoxib increased early apoptosis by $25 \%$ at $0.25 \mathrm{~J} / \mathrm{cm}^{2}$ and by $30 \%$ at $0.75 \mathrm{~J} / \mathrm{cm}^{2}$, respectively. In contrast, the number of necrotic cells did not significantly increase with the treatment condition or light intensity.

\section{$\mathrm{HO}-\mathrm{I}$ expression induced by combined treatment of ALA-PDT and celecoxib}

The highest expression of HO-1 in HuCC-T1 cells was obtained at 4 hours after irradiation (Figure S2A). This time point was used for subsequent experiments. HO-1 expression gradually increased until a maximum was reached with $3 \mathrm{mM}$ ALA-PDT, but its expression decreased with $5 \mathrm{mM}$ ALA-PDT (Figure S2B). Celecoxib did not induce HO-1 expression regardless of irradiation (Figure 4). ALA-PDT induced higher HO-1 expression after irradiation with 0.25 or $0.75 \mathrm{~J} / \mathrm{cm}^{2}$ when compared with expression levels produced in the dark (Figure 4). At a light intensity of 0.25 or $0.75 \mathrm{~J} / \mathrm{cm}^{2}$, HO-1 expression increased depending on ALA concentration until a maximum was reached at $3 \mathrm{mM}$ (Figure S2). HO-1 expression was significantly affected by the combined ALA-PDT application when compared to ALA alone. It was dependent on light intensity and celecoxib concentration, even though treatment solely with celecoxib did not affect HO-1 expression (Figure 4). When $3 \mathrm{mM}$ ALA and $10 \mu \mathrm{M}$ celecoxib were applied in combination to HuCC-T1 cells, HO-1 expression increased 5.1 fold at $0.25 \mathrm{~J} / \mathrm{cm}^{2}$ and 8.5 fold at $0.75 \mathrm{~J} / \mathrm{cm}^{2}$, when compared to the dark condition. In particular, the combination of celecoxib and ALA influenced HO-1 expression even without irradiation (Figure 4).

\section{Effects of HO-I inhibition with combined treatment of ALA-PDT and celecoxib}

We investigated whether or not phototoxicity with the combined application of $10 \mu \mathrm{M}$ celecoxib and $3 \mathrm{mM}$ ALAPDT could be enhanced by inhibition of HO-1 expression. For HO-1 inhibition, we considered a PKC inhibitor, also known as HO-1 inhibitor or shRNA plasmid. ${ }^{32}$ A $10 \mu \mathrm{M}$ concentration of the PKC inhibitor effectively inhibited the expression of HO-1 that had been induced by the combination of celecoxib and ALA at a 0.25 or $0.75 \mathrm{~J} / \mathrm{cm}^{2}$ light dose (Figure 5A). HO-1 expression was reduced by $67 \%$ and $51 \%$ at 0.25 and $0.75 \mathrm{~J} / \mathrm{cm}^{2}$, respectively. After irradiation, cell survival was significantly decreased due to inhibition of HO-1 expression by the PKC inhibitor (Figure 5B and $\mathrm{C}$ ). This phenomenon was clearly observed at a light dose of $0.25 \mathrm{~J} / \mathrm{cm}^{2}$. Cell death increased almost three fold when compared to the combination treatment.

HO-1 shRNA plasmid also suppressed the expression of HO-1 induced by the combined treatment of the drugs at 0.25 or $0.75 \mathrm{~J} / \mathrm{cm}^{2}$ (Figure $6 \mathrm{~A}$ ). In this case, cell death was increased markedly by HO-1 inhibition in comparison with the uninhibited group, regardless of light intensity (Figure 6B and $\mathrm{C}$ ). When $3 \mathrm{mM}$ ALA and $10 \mu \mathrm{M}$ celecoxib were used to cotreat HuCC-T1 cells, including shRNA plasmid, early apoptosis in cells transfected with $\mathrm{HO}-1$ shRNA plasmid increased from $26 \%$ to $37 \%$ at $0.25 \mathrm{~J} / \mathrm{cm}^{2}$ and from $34 \%$ to

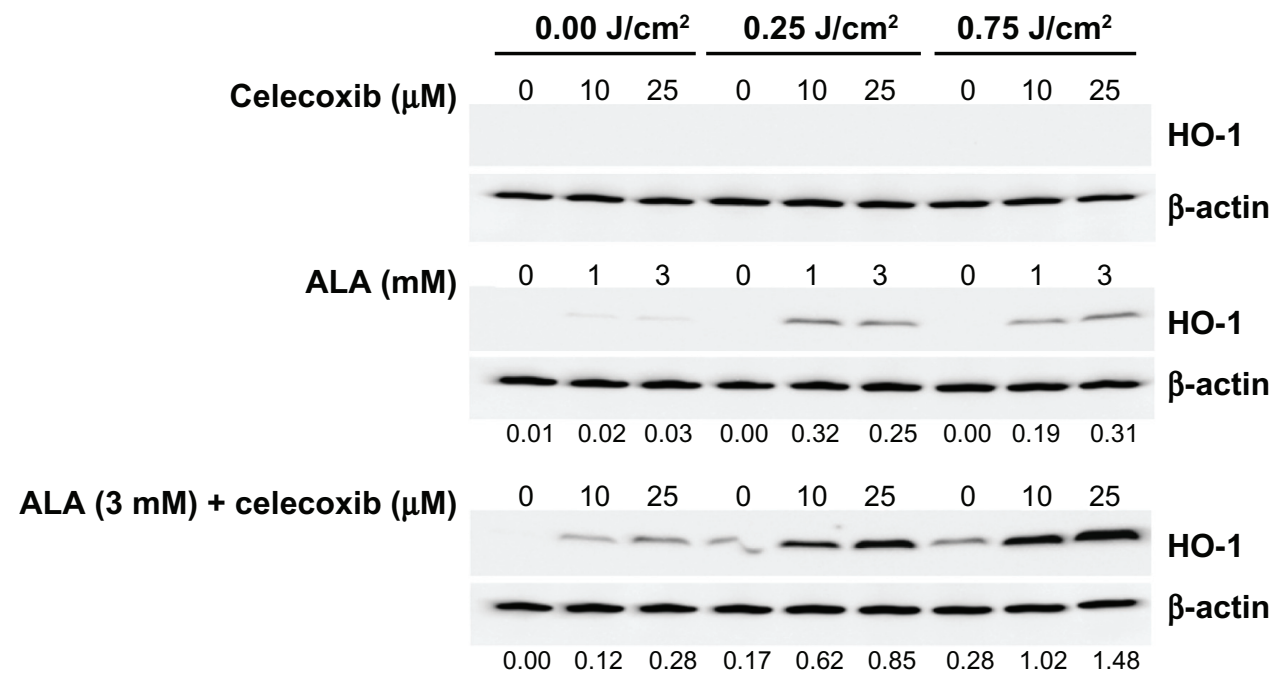

Figure 4 Heme oxygenase-I (HO-I) expression induced by treatment with 5-aminolevulinic acid (ALA) and/or celecoxib.

Notes: HuCC-TI cells were treated with ALA and/or celecoxib for 4 hours in serum-free medium. After irradiation, these cells were incubated for 4 hours in growth medium containing $10 \%$ fetal bovine serum. Cells were collected and washed with phosphate buffered saline. The pellets were lysed and HO-I expression was analyzed by immunoblot. The protein amount was corrected for by $\beta$-actin. The intensity of western band was obtained by calculating HO-I/ $\beta$-actin using the Image J program. Available at: http://rsbweb.nih.gov/ij/. $(n=3)$.

Abbreviations: ALA, 5-aminolevulinic acid; HO-I, heme oxygenase-I. 
A

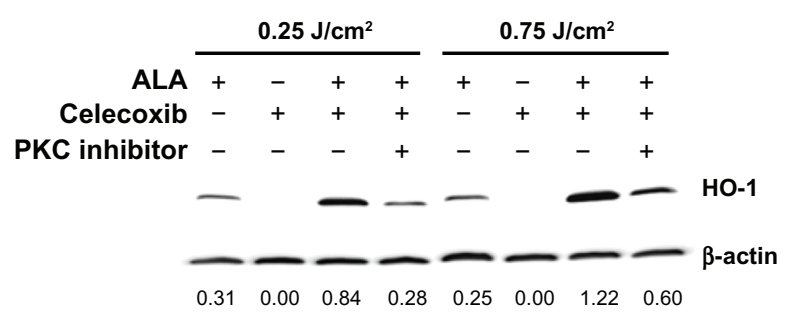

B

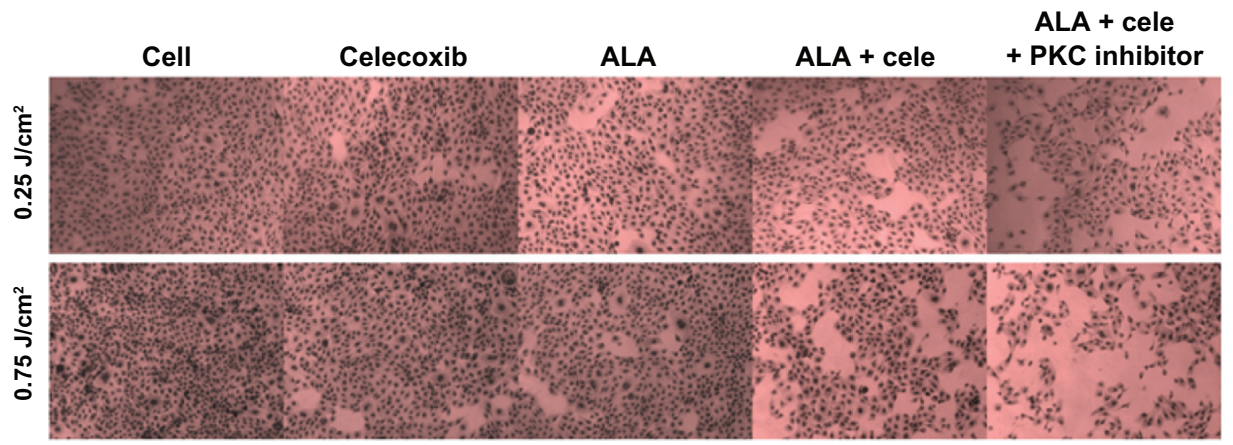

C

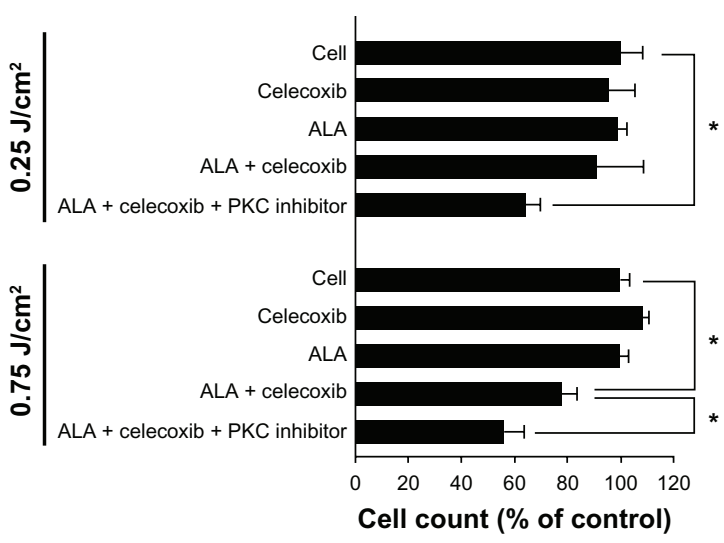

Figure 5 Effects of heme oxygenase-I (HO-I) inhibition by a protein kinase $\mathrm{C}$ (PKC) inhibitor.

Notes: HuCC-TI cells were treated with a single or combined application of 5 -aminolevulinic acid ([ALA] $3 \mathrm{mM})$, celecoxib (I0 $\mu$ M), and PKC inhibitor (I0 $\mu$ M) for 4 hours in serum-free medium. (A) After 4 hours of irradiation, cell extracts were subjected to immunoblot analysis. The intensity of western band was obtained by calculating $\mathrm{HO}$ $I / \beta$-actin using the Image J program $(n=3)$. (B) After irradiation, these cells were incubated for 24 hours in growth medium containing $10 \%$ fetal bovine serum. Cells were washed with phosphate buffered saline and stained with hematoxylin-eosin solution $(n=3)$. (C) Cells were washed with phosphate buffered saline, trypsinized, and counted $(\mathrm{n}=6$; data are represented as mean \pm SEM). * denotes $P<0.05$.

Abbreviations: ALA, 5-aminolevulinic acid; cele, celecoxib; HO-I, heme oxygenase-I; PKC, protein kinase C.

$42 \%$ at $0.75 \mathrm{~J} / \mathrm{cm}^{2}$ when compared to cells transfected with control shRNA plasmid (Figure 6D).

\section{Tumor growth inhibition by combined treatment of ALA-PDT and celecoxib in xenograft mice induced by HuCC-TI cells}

The effect of combined treatment with ALA-PDT and celecoxib was investigated in tumor bearing mice. Tumors were treated with either single or combination PDT after injection of the drugs with ALA (100 $\mathrm{mg} / \mathrm{kg})$ and celecoxib $(5 \mathrm{mg} / \mathrm{kg})$. As shown in Figure 7A and B, combined treatment with ALA and celecoxib markedly decreased tumor volume 62 days after HuCC-T1 cell injection when compared with a single treatment. The tumor volume was decreased by approximately $60 \%$ or $40 \%$, respectively, in the combined treatment (314 $\pm 72 \mathrm{~mm}^{3}$ ) with a suitable light dose in comparison to no treatment $\left(937 \pm 314 \mathrm{~mm}^{3}\right)$ or treatment with ALA alone $\left(495 \pm 137 \mathrm{~mm}^{3}\right)$. The body weights of mice did not show a significant difference (Figure S3A). Morphology of tumor tissues and apoptotic cells in tumor tissues were observed by H\&E and TUNEL staining, respectively. The tumor cell density showed an apparent difference between the single and combined treatment groups (PDT after injection combined with ALA and celecoxib). Tumor cells in the combined 
A

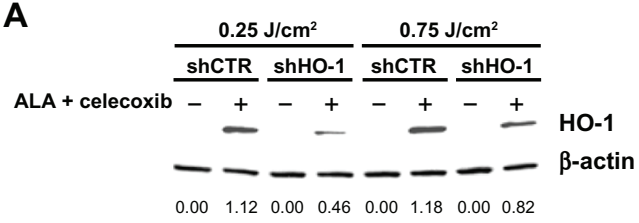

B

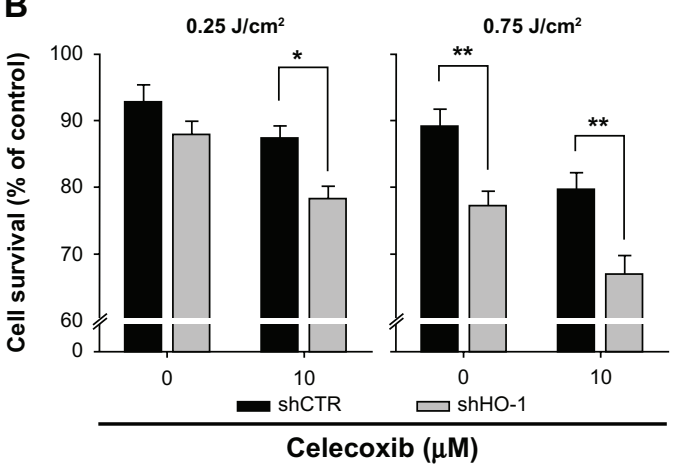

c

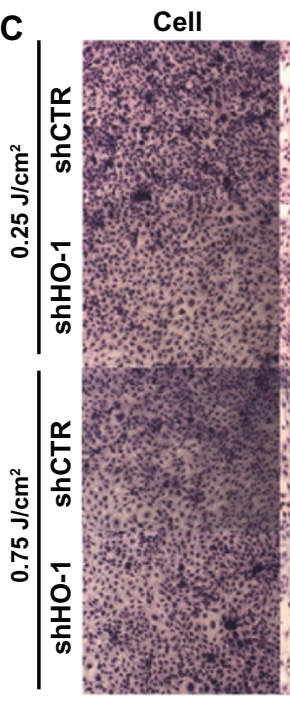

Celecoxib ALA

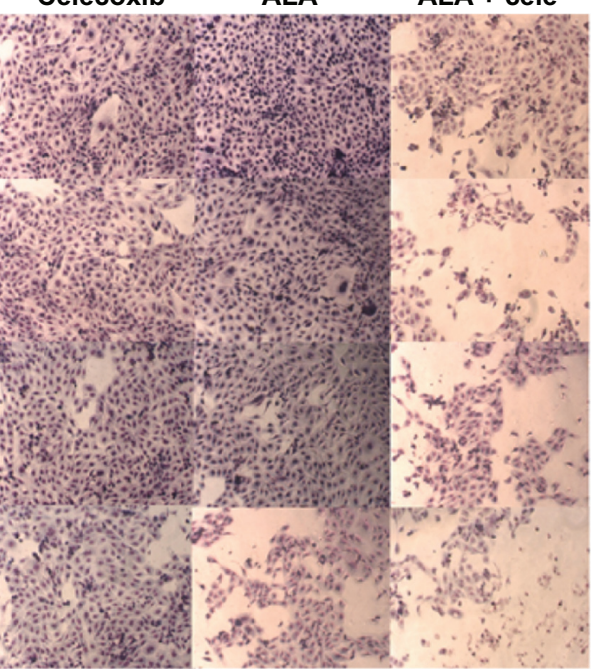

D $0.25 \mathrm{~J} / \mathrm{cm}^{2}$ $0.75 \mathrm{~J} / \mathrm{cm}^{2}$

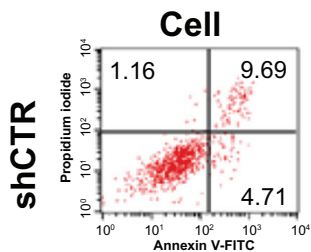

ALA + cele
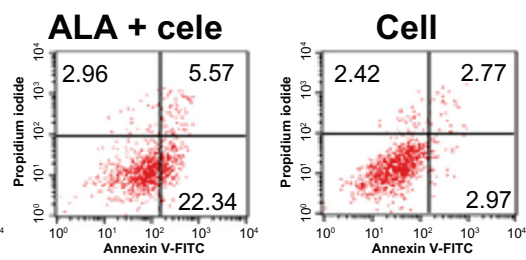

ALA + cele
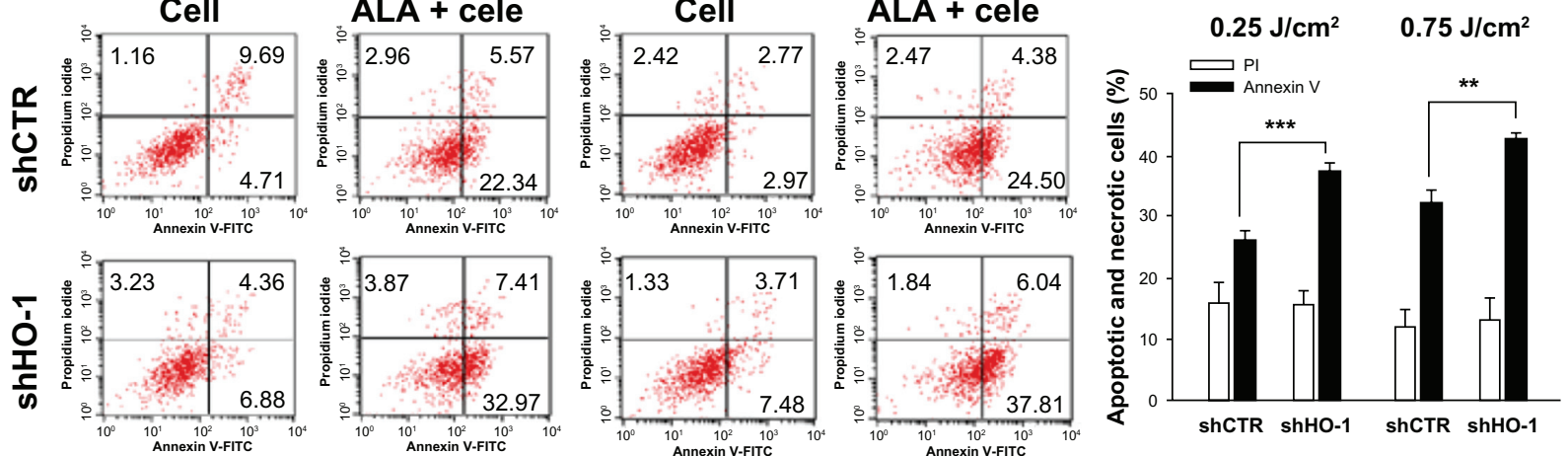

Figure 6 Effects of heme oxygenase-I (HO-I) inhibition by HO-I small hairpin RNA (shRNA).

Notes: HuCC-TI cells were transfected with control shRNA or HO-I shRNA. Twenty-four hours after transfection, cells were treated with 5-aminolevulinic acid ([ALA] $3 \mathrm{mM}$ ) and/or celecoxib $(10 \mu \mathrm{M})$ for 4 hours and irradiated with 0.25 or $0.75 \mathrm{~J} / \mathrm{cm}^{2}$. (A) Cell extracts were subjected to immunoblot analysis. The intensity of western band was obtained by calculating HO-I/ $\beta$-actin using the Image J program $(n=3)$. (B) Cell survival was determined by the MTT assay. (C) Cells were washed with phosphate buffered saline and stained with hematoxylin-eosin solution $(n=3)$. (D) The collected pellets were stained with propidium iodide and fluorescein isothiocyanate-annexin $V$ and analyzed by flow cytometry. The right graph of panel $D$ shows flow cytometry results for combined treatment with ALA and celecoxib ( $n=3$ ). Data are represented as mean \pm SEM. * denotes $P<0.05$; ** denotes $P<0.01$; and *** denotes $P<0.001$.

Abbreviations: ALA, 5-aminolevulinic acid; cele, celecoxib; HO-I, heme oxygenase-I; shCTR, control shRNA; shHO-I, HO-I shRNA.

treatment group exhibited a more sparse appearance than that observed with the single treatment, whereas tumor tissues in the nontreatment group showed the densest morphology (Figure 7C). No difference in apoptosis was evident between the single and combined treatment groups. TUNEL positive cells were not detectable as PDT was performed 21 days after HuCC-T1 injection. The tumor was dissected 41 days after PDT (Figure S3B).

\section{Discussion}

ROS generation is crucial in ALA-PDT against cancer. Accumulation of ROS in substantial concentrations damages cellular DNA and/or membranes, and induces cell death. ${ }^{9-14}$ We have previously reported that ALA-PDT could effectively inhibit HuCC-T1 cell survival via increased production of intracellular ROS. ${ }^{19}$ To further improve the effect of ALAPDT on HuCC-T1 cells, we sought to boost ROS levels after PDT. Celecoxib is considered to be a good additive drug candidate for boosting intracellular ROS levels.

When HEK 293T or HuCC-T1 cells were treated with $3 \mathrm{mM}$ ALA for 4 hours, cytotoxicity or dark toxicity was not significantly affected (Figure 1). Interestingly, PpIX generation during $1 \mathrm{mM}$ ALA treatment was affected by the presence of celecoxib, and consequently PpIX production decreased (Figure 2A). However, the generation of PpIX observed at $3 \mathrm{mM}$ ALA treatment was unaffected by the presence of celecoxib. The precise reason for the effect of celecoxib is unknown, but it could be due to the effect of 
A

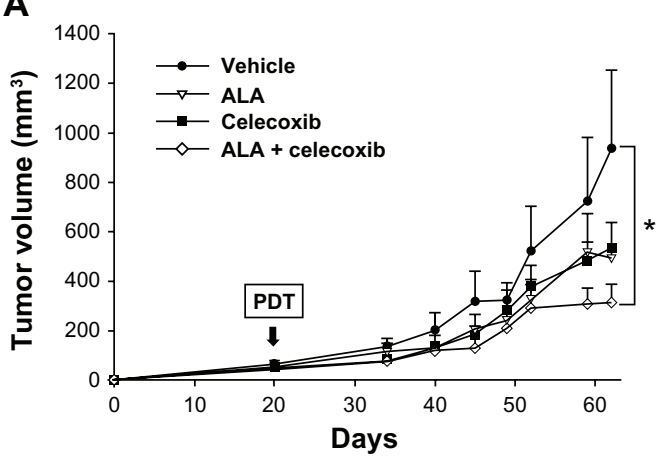

B

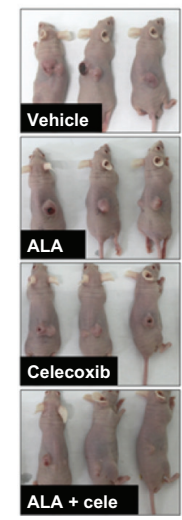

C

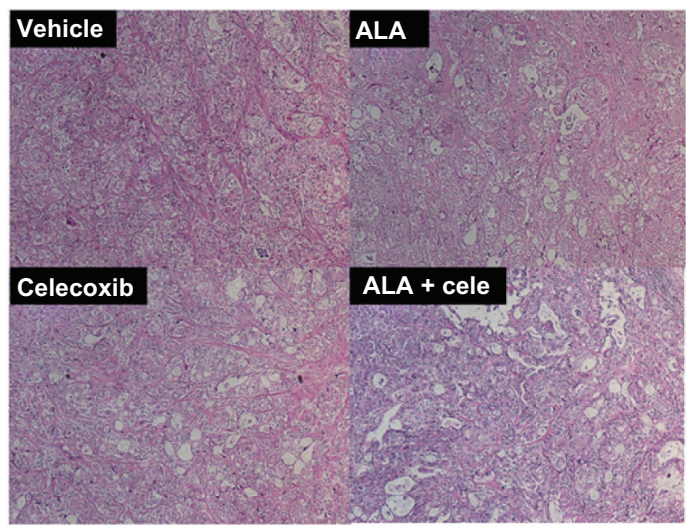

Figure 7 In vivo tumor growth inhibition by treatment with 5-aminolevulinic acid (ALA) photodynamic therapy (PDT) and/or celecoxib.

Notes: Developed tumors were treated directly with ALA (100 mg/kg) and/or celecoxib $(5 \mathrm{mg} / \mathrm{kg})$. (A) Tumor volumes were measured every $3-4$ days from 2 weeks after PDT $(n=8)$. (B) Images of tumor bearing mice and dissected tumors captured 42 days after PDT. Each graduation on the scale represents I mm. (C) The morphology of tumor tissues was observed by hematoxylin-eosin in tissue sections $(n=3)$. Error bars represent \pm SEM and $*$ denotes $P<0.05$.

Abbreviation: ALA, 5-aminolevulinic acid; cele, celecoxib.

celecoxib on some of the key enzymes involved in PpIX generation. This possibility will be investigated in future studies.

Considering the above reasons, we fixed the ALA concentration at $3 \mathrm{mM}$ and observed the effect of 10 or $25 \mu \mathrm{M}$ celecoxib in ALA-PDT. When HuCC-T1 cells were cotreated with $3 \mathrm{mM}$ ALA and 10 or $25 \mu \mathrm{M}$ celecoxib for 4 hours, the intracellular ROS levels and early apoptotic signals after irradiation increased in proportion to the celecoxib dose at light intensities of both 0.25 and $0.75 \mathrm{~J} / \mathrm{cm}^{2}$ (Figure 3B and D). However, the phototoxicity values differed when compared with the apoptotic signal (Figure 3A and D). Even though ROS and early apoptotic signals were increased at the light intensity of $0.25 \mathrm{~J} / \mathrm{cm}^{2}$, cell survival was not affected after the combined treatment (Figure 3A). Conversely, cell death increased by about $30 \%$ when treated with the combination of $3 \mathrm{mM}$ ALA and 10 or $25 \mu \mathrm{M}$ celecoxib at the light intensity of $0.75 \mathrm{~J} / \mathrm{cm}^{2}$, compared to treatment with ALA alone. These results provide a clear indication that the combination of ALA and celecoxib could successfully enhance the ALA-PDT effect under a suitable light intensity. For effective anticancer therapy using PDT, sufficient ROS generation or adequate light power would be required.

Although ROS generation or early apoptotic signals were induced successfully in the treatments with the combination of ALA and celecoxib after irradiation at $0.25 \mathrm{~J} / \mathrm{cm}^{2}$, cell death was not observed. These results suggest that a protective mechanism was activated when cells encountered oxidative stress. HO-1 is an inducible stress protein that confers cytoprotection against oxidative injury and cellular stress, both in vitro and in vivo. ${ }^{1,10}$ Furthermore, it has been reported that HO-1 protein expression was elevated by ALAPDT, and phototoxicity increased when HO-1 expression was suppressed. ${ }^{1,22}$ Therefore, the expression of HO-1 after PDT treatment was investigated in HuCC-T1 cells.

Celecoxib did not affect the expression of HO-1 regardless of light intensity (Figure 4). HO-1 expression was also not observed in HuCC-T1 cells treated with celecoxib alone for 4 hours. This could be because the concentration of celecoxib $(25 \mu \mathrm{M})$ during incubation for 4 hours is not sufficient to induce cell death (Figure 1A). In contrast, ALA 
treatment induced HO-1 expression in irradiated cells. In particular, cells cotreated with ALA and celecoxib significantly increased HO-1 expression, which increased with increasing celecoxib concentrations or light intensity. These results once again indicate that treatment with the combination of celecoxib and ALA-PDT increase the oxidative stress more than celecoxib or ALA-PDT alone at strong light intensity. We hypothesized that the effect of the combination would be further enhanced by inhibition of HO-1 expression, ie, oxidative stress to HuCC-T1 cells through ALA-PDT and celecoxib could be further enhanced when defensive mechanisms, such as HO-1 expression against oxidative stress, are blocked.

To confirm the defensive function of HO-1 against ALA-PDT generated oxidative stress, HO-1 expression was suppressed using Sn-, Co-, and Zn-PpIX, which are HO-1 inhibitors. ${ }^{34,35}$ Unfortunately, we could not obtain satisfactory results from the HO-1 inhibition experiments (Figure S4). Therefore, the PKC inhibitor, which is also a HO-1 inhibitor, ${ }^{32,33}$ and HO-1 shRNA, was used for inhibiting HO-1 expression in HuCC-T1 cells (Figures 5 and 6). Even though the PKC inhibitor is not specific or selective, it is a good inhibitor of HO-1 expression. ${ }^{32,33}$ Both the PKC inhibitor and the HO-1 shRNA plasmid could successfully inhibit HO-1 expression, which increased after PDT using the combined treatment of ALA and celecoxib (Figures 5A and 6A). Cell death also increased due to both the PKC inhibitor and HO-1 shRNA treatment with the combination depending on the light intensity (Figures 5B and C, 6B and C). Therefore, these results confirmed that the combination of ALA-PDT and celecoxib generated high levels of oxidative stress through which cell death was elevated. Defensive mechanisms such as HO-1 expression protect HuCC-T1 cells, and decrease the phototoxicity in ALA-PDT with celecoxib.

Finally, the effect of the combined treatment of ALAPDT and celecoxib on tumors induced by HuCC-T1 cells on the backs of mice was investigated. As shown in Figure 7A and $\mathrm{B}$, the combined treatment of ALA and celecoxib inhibited tumor growth more than a treatment of ALA-PDT or celecoxib alone. After the combined drug treatment, tumor tissues were morphologically sparser in appearance than those with the single treatment (Figure 7C). Although the combined treatment was injected only once and incubated for short times in mice xenografts, it still inhibited tumor growth effectively.

In conclusion, the effect of ALA-PDT could be increased by addition of celecoxib, through augmentation of oxidative stress. Therefore, combined treatment of ALA-
PDT and celecoxib would be a potential therapy for treating cholangiocarcinoma. In addition, use of a HO-1 inhibitor with ALA-PDT could play an important role in the management of various tumors.

\section{Acknowledgments}

The authors are very grateful to Mrs Eun Jin Ryu and Bo Ram Kang for their skillful technical assistance. We thank Professor Sae Ock Oh for providing the technical information mentioned in the Materials and Methods. This study was supported by a grant of the Korean Healthcare Technology R\&D Project, Ministry of Health and Welfare, Republic of Korea (Project No A091047).

\section{Disclosure}

The authors declare no conflicts of interest in this work.

\section{References}

1. Grimm S, Mvondo D, Grune T, Breusing N. The outcome of 5-ALAmediated photodynamic treatment in melanoma cells is influenced by vitamin C and heme oxygenase-1. Biofactors. 2011;37(1):17-24.

2. Moon YH, Park JH, Kim SA, Lee JB, Ahn SG, Yoon JH. Anticancer effect of photodynamic therapy with hexenyl ester of 5-aminolevulinic acid in oral squamous cell carcinoma. Head Neck. 2010;32(9):1136-1142.

3. Malik Z, Kostenich G, Roitman L, Ehrenberg B, Orenstein A. Topical application of 5-aminolevulinic acid, DMSO and EDTA: protoporphyrin IX accumulation in skin and tumours of mice. J Photochem Photobiol B. 1995;28(3):213-218.

4. Peng Q, Berg K, Moan J, Kongshaug M, Nesland JM. 5-Aminolevulinic acid-based photodynamic therapy: principles and experimental research. Photochem Photobiol. 1997;65(2):235-251.

5. Peng Q, Warloe T, Berg K, et al. 5-Aminolevulinic acid-based photodynamic therapy. Clinical research and future challenges. Cancer. 1997;79(12):2282-2308.

6. De Rosa FS, Marchetti JM, Thomazini JA, Tedesco AC, Bentley MV. A vehicle for photodynamic therapy of skin cancer: influence of dimethylsulphoxide on 5-aminolevulinic acid in vitro cutaneous permeation and in vivo protoporphyrin IX accumulation determined by confocal microscopy. J Control Release. 2000;65(3):359-366.

7. Peng Q, Warloe T, Moan J, et al. Antitumor effect of 5-aminolevulinic acid-mediated photodynamic therapy can be enhanced by the use of a low dose of photofrin in human tumor xenografts. Cancer Res. 2001;61(15):5824-5832.

8. Alvarez MG, Lacelli MS, Rivarola V, Batlle A, Fukuda H. 5-aminolevulinic acid-mediated photodynamic therapy on Hep-2 and MCF-7c3 cells. J Environ Pathol Toxicol Oncol. 2007;26(2):75-82.

9. Pierre MB, Tedesco AC, Marchetti JM, Bentley MV. Stratum corneum lipids liposomes for the topical delivery of 5-aminolevulinic acid in photodynamic therapy of skin cancer: preparation and in vitro permeation study. BMC Dermatol. 2001;1:5.

10. Frank J, Lornejad-Schafer MR, Schoffl H, Flaccus A, Lambert C, Biesalski HK. Inhibition of heme oxygenase-1 increases responsiveness of melanoma cells to ALA-based photodynamic therapy. Int J Oncol. 2007;31(6):1539-1545.

11. Sharma S, Jajoo A, Dube A. 5-Aminolevulinic acid-induced protoporphyrin-IX accumulation and associated phototoxicity in macrophages and oral cancer cell lines. J Photochem Photobiol B. 2007;88(2-3):156-162.

12. Chen R, Huang Z, Chen G, et al. Kinetics and subcellular localization of 5-ALA-induced PpIX in DHL cells via two-photon excitation fluorescence microscopy. Int J Oncol. 2008;32(4):861-867. 
13. Donnelly RF, McCarron PA, Woolfson AD. Derivatives of 5-aminolevulinic Acid for photodynamic therapy. Perspect Medicin Chem. 2008;1:49-63.

14. Fotinos N, Mikulic J, Convert M, et al. 5-ALA derivative-mediated photoinactivation of Propionibacterium acnes. J Dermatol Sci. 2009; 56(3):214-216.

15. Chung CW, Kim CH, Choi KH, et al. Effect of surfactant on 5-aminolevulinic acid uptake and PpIX generation in human cholangiocarcinoma cell. Eur J Pharm Biopharm. 2012;80(2):453-458.

16. Yang SJ, Shieh MJ, Lin FH, et al. Colorectal cancer cell detection by 5-aminolaevulinic acid-loaded chitosan nano-particles. Cancer Lett. 2009;273(2):210-220.

17. Battah S, Balaratnam S, Casas A, et al. Macromolecular delivery of 5-aminolaevulinic acid for photodynamic therapy using dendrimer conjugates. Mol Cancer Ther. 2007;6(3):876-885.

18. Dognitz N, Salomon D, Zellweger M, et al. Comparison of ALA- and ALA hexyl-ester-induced PpIX depth distribution in human skin carcinoma. J Photochem Photobiol B. 2008;93(3):140-148.

19. Kim CH, Chung CW, Choi KH, et al. Effect of 5-aminolevulinic acidbased photodynamic therapy via reactive oxygen species in human cholangiocarcinoma cells. Int J Nanomedicine. 2011;6:1357-1363.

20. Wu T, Leng J, Han C, Demetris AJ. The cyclooxygenase-2 inhibitor celecoxib blocks phosphorylation of Akt and induces apoptosis in human cholangiocarcinoma cells. Mol Cancer Ther. 2004;3(3): 299-307.

21. Hsu AL, Ching TT, Wang DS, Song X, Rangnekar VM, Chen CS. The cyclooxygenase-2 inhibitor celecoxib induces apoptosis by blocking Akt activation in human prostate cancer cells independently of Bcl-2. J Biol Chem. 2000;275(15):11397-11403.

22. Ohgari Y, Miyata Y, Miyagi T, et al. Roles of porphyrin and iron metabolisms in the delta-aminolevulinic acid (ALA)-induced accumulation of protoporphyrin and photodamage of tumor cells. Photochem Photobiol. 2011;87(5):1138-1145.

23. Miyagiwa M, Ichida T, Tokiwa T, Sato J, Sasaki H. A new human cholangiocellular carcinoma cell line (HuCC-T1) producing carbohydrate antigen 19/9 in serum-free medium. In Vitro Cell Dev Biol. 1989;25(6):503-510.

24. Heo HY, Park JM, Kim CH, Han BS, Kim KS, Seol W. LRRK2 enhances oxidative stress-induced neurotoxicity via its kinase activity. Exp Cell Res. 2010;316(4):649-656.
25. Pederson LC, Buchsbaum DJ, Vickers SM, et al. Molecular chemotherapy combined with radiation therapy enhances killing of cholangiocarcinoma cells in vitro and in vivo. Cancer Res. 1997;57(19):4325-4332.

26. Watanabe $\mathrm{Y}$, Asano $\mathrm{R}$, Arai $\mathrm{K}$, et al. In vitro and in vivo antitumor effects of recombinant bispecific antibodies based on humanized antiEGFR antibody. Oncol Rep. 2011;26(4):949-955.

27. Plengsuriyakarn T, Viyanant V, Eursitthichai V, et al. Anticancer activities against cholangiocarcinoma, toxicity and pharmacological activities of Thai medicinal plants in animal models. BMC Complement Altern Med. 2012;12:23.

28. Lv Y, Fang M, Zheng J, et al. Low-intensity ultrasound combined with 5 -aminolevulinic acid administration in the treatment of human tongue squamous carcinoma. Cell Physiol Biochem. 2012;30(2):321-333.

29. Sugiyama H, Onuki K, Ishige $K$, et al. Potent in vitro and in vivo antitumor activity of sorafenib against human intrahepatic cholangiocarcinoma cells. J Gastroenterol. 2011;46(6):779-789.

30. Kim $\mathrm{JH}$, Lee $\mathrm{JH}$, Kim $\mathrm{KS}$, et al. Intratumoral delivery of paclitaxel using a thermosensitive hydrogel in human tumor xenografts. Arch Pharm Res. 2013;36(1):94-101.

31. Calin MA, Gruia M, Herascu N, Coman T. The monitoring of the accumulation of protoporphyrin IX in Walker tumours by subcutaneous administration of delta-aminolevulinic acid. J Exp Ther Oncol. 2004;4(3):247-251.

32. Yun BR, Lee MJ, Kim JH, Kim IH, Yu GR, Kim DG. Enhancement of parthenolide-induced apoptosis by a PKC-alpha inhibition through heme oxygenase-1 blockage in cholangiocarcinoma cells. Exp Mol Med. 2010;42(11):787-797.

33. Chiou YS, Tsai ML, Nagabhushanam K, et al. Pterostilbene is more potent than resveratrol in preventing azoxymethane (AOM)-induced colon tumorigenesis via activation of the NF-E2-related factor 2 (Nrf2)-mediated antioxidant signaling pathway. J Agric Food Chem. 2011;59(6):2725-2733.

34. Yoon JH, Yoon HE, Kim O, Kim SK, Ahn SG, Kang KW. The enhanced anti-cancer effect of hexenyl ester of 5-aminolaevulinic acid photodynamic therapy in adriamycin-resistant compared to non-resistant breast cancer cells. Lasers Surg Med. 2012;44(1):76-86.

35. Okimura Y, Fujita H, Ogino T, et al. Regulation of 5-aminolevulinic acid-dependent protoporphyrin IX accumulations in human histiocytic lymphoma U937 cells. Physiol Chem Phys Med NMR. 2007;39(1):69-82. 


\section{Supplementary figures}

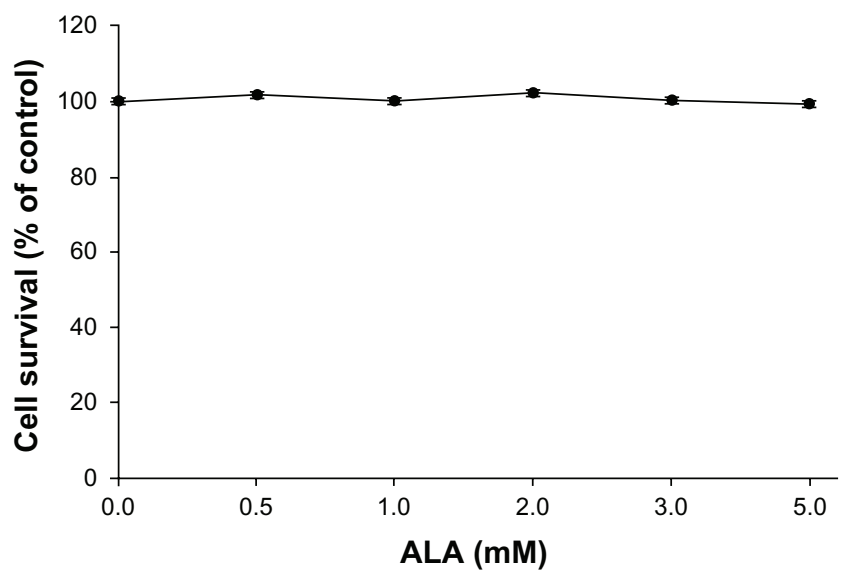

Figure SI 5-aminolevulinic acid (ALA) cytotoxicity in HEK 293T cells.

Notes: HEK 293T cells were starved for 24 hours in medium containing $0.1 \%$ fetal bovine serum. The cells were treated with various concentrations of ALA for 4 hours in medium containing $0.1 \%$ fetal bovine serum. Cell survival was determined by the MTT assay. Error bars represent \pm SEM. Abbreviation: ALA, 5-aminolevulinic acid.

\section{A}

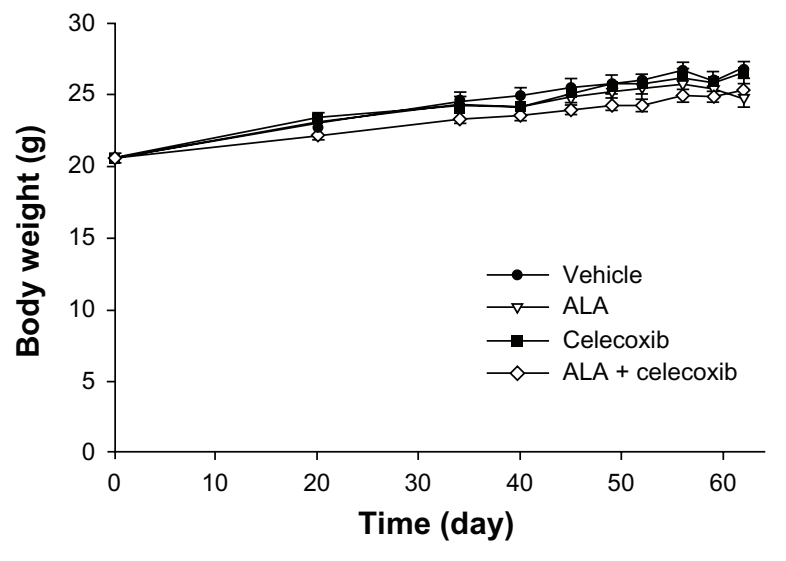

A $0.25 \mathrm{~J} / \mathrm{cm}^{2}$

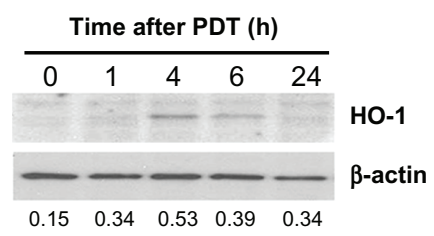

B

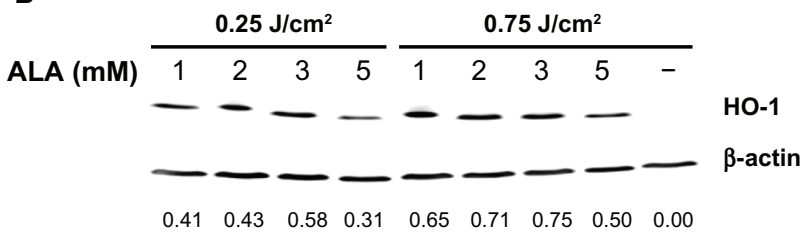

Figure S2 Heme oxygenase-I (HO-I) expression according to time and 5-aminolevulinic acid (ALA) dose after photodynamic therapy.

Notes: (A) HuCC-TI cells were treated with ALA $(0.5 \mathrm{mM})$ and incubated for 4 hours. After irradiation with a light intensity of $0.25 \mathrm{~J} / \mathrm{cm}^{2}$, these cells were incubated for $0,1,4,6$, and 24 hours in growth medium containing $10 \%$ fetal bovine serum. (B) Cells were treated with various ALA concentrations (I, 2, 3, and $5 \mathrm{mM}$ ). After irradiation with 0.25 or $0.75 \mathrm{~J} / \mathrm{cm}^{2}$, they were incubated for 4 hours in growth medium containing $10 \%$ fetal bovine serum. The cells were collected and washed with phosphate buffered saline. The pellets were lysed and $\mathrm{HO}-\mathrm{I}$ expression was analyzed by immunoblot. The protein amount was corrected for by $\beta$-actin. The numerical value of bottom was obtained by calculating $\mathrm{HO}-\mathrm{I} / \beta$-actin using the Image J program $(\mathrm{n}=3)$.

Abbreviations: ALA, 5-aminolevulinic acid; PDT, photodynamic therapy; HO-I, heme oxygenase-I.

\section{B}

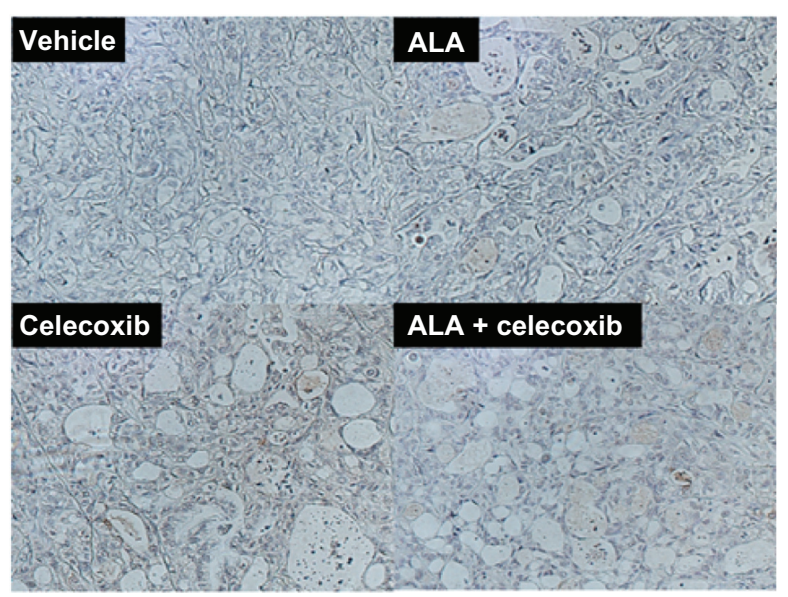

Figure S3 Body weight and apoptotic cells after treatment with 5-aminolevulinic acid (ALA) photodynamic therapy (PDT) and/or celecoxib.

Notes: Developed tumors were treated directly with ALA (100 mg/kg) and/or celecoxib $(5 \mathrm{mg} / \mathrm{kg})$. (A) The body weights of mice were measured every $3-4$ days from 2 weeks after PDT $(n=8$; error bars represent \pm SEM). (B) At 42 days after PDT, apoptotic cells in tumor tissues were observed by terminal deoxynucleotidyl transferase dUTP nick end labeling staining $(n=3)$.

Abbreviation: ALA, 5-aminolevulinic acid. 


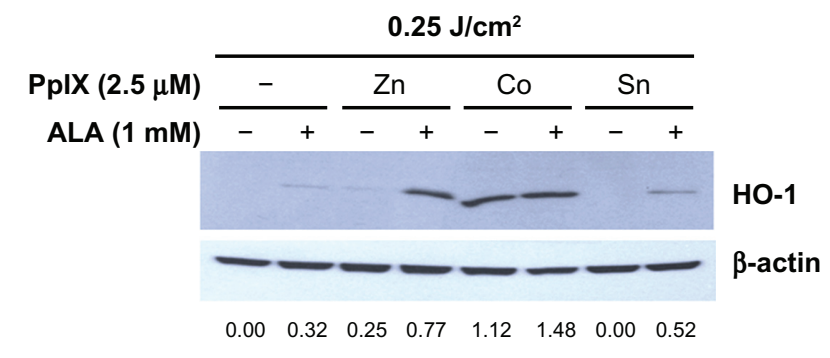

Figure S4 Effect of heme oxygenase-I (HO-I) inhibition by $\mathrm{Zn}-$, Co-, and Snprotoporphyrin IX, and HO-I inhibitor.

Notes: HuCC-TI cells were treated with 5 -aminolevulinic acid ([ALA] I mM) and/or HO-I inhibitors $(2.5 \mu \mathrm{M})$. After incubation for 4 hours, cells were irradiated with a light intensity of $0.25 \mathrm{~J} / \mathrm{cm}^{2}$. At 4 hours after irradiation, cells were collected and washed with phosphate buffered saline. The pellets were lysed and $\mathrm{HO}-\mathrm{I}$ expression was analyzed by immunoblot. The protein amount was corrected for by $\beta$-actin. The numerical value of bottom was obtained by calculating $\mathrm{HO}-\mathrm{I} / \beta$-actin using the Image J program $(\mathrm{n}=3)$.

Abbreviations: ALA, 5-aminolevulinic acid; HO-I, heme oxygenase-I; PpIX, protoporphyrin IX.

\section{Publish your work in this journal}

The International Journal of Nanomedicine is an international, peerreviewed journal focusing on the application of nanotechnology in diagnostics, therapeutics, and drug delivery systems throughout the biomedical field. This journal is indexed on PubMed Central, MedLine, CAS, SciSearch $\AA$, Current Contents ${ }^{\circledR} /$ Clinical Medicine,
Journal Citation Reports/Science Edition, EMBase, Scopus and the Elsevier Bibliographic databases. The manuscript management system is completely online and includes a very quick and fair peer-review system, which is all easy to use. Visit http://www.dovepress.com/ testimonials.php to read real quotes from published authors. 